NASA Technical Memorandum 102111

\title{
Diamondlike Carbon Protective Coatings for Optical Windows
}

Diane M. Swec and Michael J. Mirtich

Lewis Research Center

Cleveland, Ohio

Prepared for the 1989 Technical Symposia on Aerospace Sensing sponsored by The International Society for Optical Engineering Orlando, Florida, March 27-31, 1989

\section{N/SA}




\title{
DIAMONDLIKE CARBON PROTECTIVE COATINGS FOR OPTICAL WINDOWS
}

\author{
Diane M. Swec and Michael J. Mirtich \\ National Aeronautics and Space Administration \\ Lewis Research Center \\ Cleveland, Ohio 44135
}

\begin{abstract}
SUMMARY
Dlamondlike carbon (DLC) fllms were deposited on infrared transmitting optical windows and were evaluated as protective coatings for these windows exposed to particle and rain erosion. The DLC films were deposited on zinc selenide ( $Z n S e$ ) and zinc sulfide ( $Z n S$ ) by three different ion beam methods: (1) sputter deposition from a carbon target using an 8-cm argon ion source, (2) direct deposition by a $30-\mathrm{cm}$ hollow cathode ion source with hydrocarbon gas in argon, and ( 3 ) dual beam direct deposition by the $30-\mathrm{cm}$ hollow cathode ion source and an $8-\mathrm{cm}$ argon ion source. In an attempt to improve the adherence of the DLC films on ZnSe and ZnS, ion beam cleaning, ion implantation with helium and neon ions, or sputter deposition of a thin, ion beam intermediate coating was employed prior to deposition of the DLC film. The protection that the DLC flims afforded the windows from particle and rain erosion was evaluated, along with the hydrogen content, adherence, intrinsic stress, and infrared transmittance of the fllms. Because of elevated stress levels in the lon beam sputtered DLC flims and in those ion beam deposited with butane, films thicker than $0.1 \mathrm{\mu m}$ and with good adherence on $\mathrm{ZnS}$ and $\mathrm{ZnSe}$ could not be generated. An intermediate coating of germanium successfully allowed the DLC films to remain adherent to the optical windows and caused only a negligible reduction in the specular transmittance of the $\mathrm{ZnS}$ and $\mathrm{ZnSe}$ at $10 \mu \mathrm{m}$. These DLC films did not protect the optical windows from simulated particle erosion; however, they did improve the performance of $\mathrm{ZnS}$ exposed to rain erosion.
\end{abstract}

\section{INTRODUCTION}

Infrared-transparent materials, such as zinc sulfide ( $Z n S$ ) and zinc selenide ( $Z n S e)$, are those most often used as optical windows. However, these materials are soft and undergo serious degradation when subjected to severe particle-impacting environmental conditions (ref. 1). Therefore, attempts have been made to harden these window surfaces to protect them from sand or rain impact.

Hard thin films may be used to maintain the optical integrity of infrared windows. The desired films must be adherent and durable such that they protect $\mathrm{ZnS}$ and $\mathrm{ZnSe}$ windows from particle and rain erosion as well as chemical attack. A low film-stress level is also desirable so that a thick layer of these hard films can be deposited for maximum protection of the soft materials. One film with this potential is damondlike carbon (DLC) (refs. I and 2). DLC films are transparent over a broad spectral range, resist chemical attack, and are moisture and abrasion resistant.

Three different ion beam methods were used to deposit DLC films on fused sllica $\left(\mathrm{SiO}_{2}\right)$, silicon ( $\left.\mathrm{Si}\right), \mathrm{ZnS}$, and $\mathrm{ZnSe}$ : (1) sputter deposition from a carbon target by an 8-cm argon ion source, (2) direct deposition by a 30-cm 
hollow cathode ion source with hydrocarbon gas in argon ( $A r$ ), and ( 3 ) dual beam direct deposition by the 30-cm hollow cathode and an 8-cm argon ion source. To improve the adherence of the DLC films on $\mathrm{ZnS}$ and $\mathrm{ZnSe}$, the following techniques were employed prior to deposition of the film: (1) ion beam cleaning, (2) Ion implantation via "knock on" of thin carbon films by 100-keV nitrogen ions, (3) ion implantation with 100-keV neon and helium ions, and (4) thin, ion beam sputter-deposited intermediate coatings of germanium (Ge) or silicon. The DLC films were then evaluated for hydrogen content, adherence, intrinsic stress, infrared transmittance, and protection from particle and rain erosion.

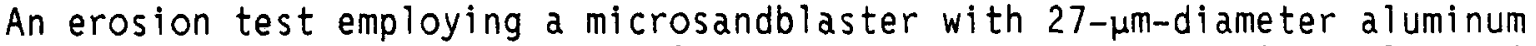
oxide $\left(\mathrm{Al}_{2} \mathrm{O}_{3}\right)$ particles was developed to determine quantitative values of the protection that the diamondlike films afforded the window surfaces. After erosion an infrared (IR) spectrophotometer was used to indicate the change in specular transmittance between 2.5 and $50 \mu \mathrm{m}$. The DLC-coated windows were also subjected to water droplets at $180 \mathrm{~m} / \mathrm{sec}$ for exposure times up to $15 \mathrm{~min}$ in a rain erosion facility at Wright Patterson Air Force Base. These samples were qualitatively evaluated by optically viewing the pitting, microcracks, and subsurface ring cracks that resulted from the erosion. The results of these studies are presented in this paper.

\section{APPARATUS AND PROCEDURE}

Diamondlike carbon films were ion beam sputter deposited from a pyrolytic graphite target by an 8-cm-diameter source (ref. 3). A 1000-eV argon ion beam was produced for sputter cleaning and deposition. The ion beam current density was $\sim 1.0 \mathrm{~mA} / \mathrm{cm}^{2}$ in the vicinity of the sputter target and substrates, which were located $20 \mathrm{~cm}$ downstream of the ion source. The ion source was operated with a hot filament neutralizer in a vacuum facility that maintained pressures of $2 \times 10^{-5}$ torr during operation. In conjunction with this method, hydrogen gas was introduced in the vacuum chamber to evaluate its effect on these films. The introduction of hydrogen gas raised the background pressure to a range of $7 \times 10^{-5}$ to $10^{-4}$ torr. Films $0.1 \mu \mathrm{m}$ thick were deposited on the various substrates.

A 30-cm-diameter ion source with its optics masked to $10 \mathrm{~cm}$ in diameter was used to directly deposit the DLC films (ref. 4). The ion source used argon gas in the hollow cathode located in the main discharge chamber, as well as in the neutralizer. Hydrocarbon gas was introduced through a manifold into the discharge chamber at a molar ratio of $0.28 \mathrm{CH}_{4}$ or $0.10 \mathrm{C}_{4} \mathrm{H}_{10}$ to argon. Typically, current densities were $1 \mathrm{~mA} / \mathrm{cm}^{2}$ at a distance of $2.5 \mathrm{~cm}$ axially downstream of the grids, and argon ion energies ranged from 90 to $250 \mathrm{eV}$.

It is believed that amorphous carbon films are produced under conditions where growth and sputtering occur simultaneously, therefore increased sputtering may decrease the number of graphite precursors incorporated in the films and hence improve the quality (ref. 4). An 8-cm ion source with a filament cathode was used during the dual beam deposition to direct a beam of 200- to $600-e V$ argon ions at a current density of $25 \mu \mathrm{A} / \mathrm{cm}^{2}$ on the substrates while the OLC film was being deposited by the 30-cm source.

The intrinsic stress of the DLC films was measured with a stress gauge, and an adherence tester was used to determine the adherence of the DLC films. The transmittance of the DLC films in the visible region was obtained with an integrating sphere, and the IR transmittance was measured with a spectrophotometer. 
An erosion test was developed that used a sandblaster to give quantitative values to the protection that the DLC films afforded fused silica (ref. 5). The fused silica surfaces were exposed to $100-\mu \mathrm{m}$-diameter $\mathrm{SiO}_{2}$ particles at $27 \mathrm{~m} / \mathrm{sec}$, and then the protective quality of the film was characterized by the resulting change in specular transmittance by a neon-helium ellipsometer. The protection that the DLC films afforded the $Z n S$ and ZnSe surfaces was quantitatively determined from another simulated particle erosion test (ref. 6 ). The window surfaces were eroded by exposing them to $27-\mu \mathrm{m}$-diameter $\mathrm{Al}_{2} \mathrm{O}_{3}$ particles with an estimated stream velocity of $335 \mathrm{~m} / \mathrm{sec}$ in a microsandblaster. The protective quality of the fllm was then characterized by the change in specular transmittance due to the particle erosion with an IR spectrophotometer between wavelengths of 2.5 and $50 \mu \mathrm{m}$.

A facility at the Wright Patterson Air Force Base was employed to evaluate the rain erosion performance of the DLC films. The rain erosion facility consisted of a variable-speed rotating arm apparatus with speeds to $210 \mathrm{~m} / \mathrm{sec}$ and a simulated rainfall of $7 \times 10^{-4} \mathrm{~cm} / \mathrm{sec}$. The rotating arm apparatus employed a horizontally mounted, 8-ft double-arm propeller blade powered by a 400-hp motor. A pipe ring containing hypodermic needles was positioned such that controlled water droplets were sprayed on the test specimens, which were mounted in the blade tips.

\section{RESULTS AND DISCUSSION}

\section{Hydrogen Content}

Nuclear reaction and combustion analys is for hydrogen was performed on the DLC films (ref. 7). This technique showed that DLC films made by the various deposition methods have very similar hydrogen depth profiles. The atomic ratio of hydrogen to carbon (H/C) was low at the film surface and rose to a constant value at a depth of $50 \mathrm{~nm}$. Table I shows the hydrogen-to-carbon ratios measured one-half of the distance through the DLC films for the three different deposition methods. There is a variation in hydrogen content which depends on the method used to deposit the DLC film. DLC films made by single ion-beam deposition with $\mathrm{CH}_{4}$ had an $\mathrm{H} / \mathrm{C}$ ratio of 0.91 . Adding the energy of the second ion source (dual beam) reduced this ratio to 0.62 . Thus, the second source removed some of the hydrogen. DLC films generated by the single source, but with $\mathrm{C}_{4} \mathrm{H}_{10}$, also had an $\mathrm{H} / \mathrm{C}$ ratio of 0.62 . The films generated by ion beam sputter deposition from a graphite target contained the least amount of hydrogen, an H/C ratio of 0.22 . The addition of up to 35 percent hydrogen gas into the vacuum facility during sputter deposition doubled the hydrogen content of these films.

Semiquantitative infrared spectroscopy was also performed on the se ion beam deposited films. The integrated intensity of the $\mathrm{C}-\mathrm{H}$ stretching band at about $3.4 \mathrm{\mu m}$ indicated that the ratio of chemically bonded hydrogen to carbon was between 0.03 and 0.44 (ref. 7 ). The difference between the two hydrogen analysis techniques indicates the presence of nonbonded hydrogen in the films. 
The DLC films deposited on Si exhibited a compressive stress that varied depending on the deposition method, hydrocarbon gas, and energy of deposition. Figures 1 to 3 show the stress levels of $0.1-\mu m$-thick DLC films made by the different ion beam deposition methods. Figure 1 is a plot of the compressive stress as a function of the $\mathrm{H} / \mathrm{Ar}$ gas ratio for $\mathrm{CH}_{4}$ and $\mathrm{C}_{4} \mathrm{H}_{10}$ gases deposited at $110 \mathrm{eV}$ by the single ion-beam source. The stress for each type of film was independent of the H/Ar ratio, but was 2.5 times as large for the $\mathrm{C}_{4} \mathrm{H}_{10}$ films as it was for the $\mathrm{CH}_{4}$ films. Figure 2 shows that the stress in the $\mathrm{CH}_{4}$ single beam films can be reduced to values as low as $4 \times 10^{9}$ dyne $/ \mathrm{cm}^{2}$ by decreasing the deposition energy to $90 \mathrm{eV}$. Figure 3 shows the compressive stress for DLC films deposited by ion sputtering a graphite target (including those films made with the addition of hydrogen). The compressive stress was $1.6 \times 10^{10} \mathrm{dyne} / \mathrm{cm}^{2}$ for a pure, sputter-deposited film and rose slightly to $2.3 \times 10^{10} \mathrm{dyne} / \mathrm{cm}^{2}$ for a film with hydrogen addition. These stress levels are higher than those for films made by direct ion beam deposition, single or dual, with $\mathrm{CH}_{4}$. Table I lists the stress levels for the various DLC films. The data indicate that the film stress does not depend on the hydrogen content, but on other parameters such as deposition technique and conditions, and hydrocarbon gas.

\section{Adherence}

The adherence of the DLC films on fused silica was measured by following the procedure used by Mirtich (ref. 8). Films up to 1 um thick, deposited by either single or dual beam systems with $\mathrm{CH}_{4}$, were at least as adherent as the maximum measurable adherence of the tester: namely, $2.8 \times 10^{6} \mathrm{~N} / \mathrm{m}^{2}$. These films were so adherent that, for some of the films, portions of the $\mathrm{SiO}_{2}$ gave way with the film still intact. Films made by the single ion-beam system with $\mathrm{C}_{4} \mathrm{H}_{10}$ began to spall once the thickness reached $0.15 \mu \mathrm{m}$, and the films that were sputter deposited from the graphite target began to spall at $0.2 \mu \mathrm{m}$ thick, indicating an upper limit of the allowable thickness of these films. This was expected, since the stress levels of these two types of DLC films were greater than those made with $\mathrm{CH}_{4}$ in either the single or dual beam.

In an attempt to improve the adherence of DLC films that were ion beam deposited on ZnS and ZnSe, four techniques were used prior to film deposition (ref. 9). Ion beam cleaning of the window materials was the first technique used, but was not sufficient, as it was with the $\mathrm{SiO}_{2}$ or $\mathrm{Si}$ substrates, to allow the DLC films to remain adherent. The films had negligible adherence $\left(<1.4 \times 10^{4} \mathrm{~N} / \mathrm{m}^{2}\right)$ and spalled almost immediately after deposition on both $\mathrm{ZnS}$ and $\mathrm{ZnSe}$. The second technique involved ion implantation via "knock on" of thin carbon films on the surface of $\mathrm{ZnS}$ and $\mathrm{ZnSe}$ by 50 to $100 \mathrm{keV}$ nitrogen ions. This technique also failed to allow the DLC films to remain adherent. In the third technique, the window surfaces were ion implanted with neon or helium at energies varying between 50 and $100 \mathrm{keV}$ and at doses from $0.5 \times 10^{17}$ to $2 \times 10^{17}$ particles $/ \mathrm{cm}^{2}$. These films spalled after a period of time. The fourth technique, which used a thin intermediate coating of germanium or silicon, successfully allowed the DLC films to remain adherent. Thin films of Ge or Si, $0.1 \mu \mathrm{m}$ thick, were ion beam sputter deposited onto ZnS and ZnSe prior to deposition of DLC. The interface of Si looked good on deposit, but spalled as a function of time and/or thickness. Germanium films as thick as $0.4 \mu \mathrm{m}$ 
exhibited adherence equal to the strength of the substrate and showed no sign of deterioration even after 6 months. DLC films deposited on ZnS and ZnSe with an intermediate Ge coating of $0.05 \mu \mathrm{m}$ showed adherence values of $10^{6}$ to $1.4 \times 10^{6} \mathrm{~N} / \mathrm{m}^{2}$, also equal to the strength of the substrate. It was also possible to obtain the same adherence values of DLC-Ge films deposited on $\mathrm{ZnS}$ and ZnSe substrates that were first Implanted with 100-keV He ions at doses to $2 \times 1017$ particles $/ \mathrm{cm}^{2}$.

A bonus of ion implantation was the improved physical hardness of the substrate, shown in figure 4 for $Z n S$. The Vickers hardness as a function of the applled load for unimplanted $Z n S$ and ZnSe was compared with that for $Z n S$ and ZnSe that were $H e$ ion implanted at $100 \mathrm{keV}$ at a dose equal to $2 \times 10^{17} \mathrm{particles} / \mathrm{cm}^{2}$. At the $5 \mathrm{-g}$ indentor load, the surface hardness for the implanted ZnS shows a dramatic 70 percent increase over the unimplanted $\mathrm{ZnS}$.

\section{Transmittance}

The transmittance of the OLC films on fused silica in the visible region was obtained by using the Bowman technique (ref. 10). The DLC films obtained from the single ion-beam deposition method with $\mathrm{CH}_{4}$ have a spectral transmittance similar to those generated by the dual beam source, but the single beam films have lower transmittance values when they are greater than $0.12 \mu \mathrm{m}$ thick. This is evident in figure 5, where the spectral transmittance is shown for DLC films, $0.15 \mu \mathrm{m}$ thick, generated by both methods. The $0.15-\mu \mathrm{m}-$ thick dual beam film has greater transmittance at all wavelengths when compared with the single beam film of the same thickness. The increased absorption most likely arises from the presence of systems of conjugated double bonds within the film, although the presence of oxygen could also play a role (ref. 11). Both the graphitic precursors and the oxygen would be expected to be reduced by the increased sputtering from the second source. A $0.05-\mu \mathrm{m}$-thick DLC film that was single ion-beam deposited from $\mathrm{CH}_{4}$ displays spectral transmittance values greater than 90 percent at wavelengths greater than $0.8 \mu \mathrm{m}$. Figure 5 also shows spectral data for a $0.17-\mu m$-thick DLC film that was ion beam sputter deposited from a graphite target. The transmittance was measured only between 0.4 and $0.8 \mu \mathrm{m}$ for this $f i l \mathrm{~m}$, and it is very low compared with the DLC films that were direct deposited. The low transmittance of the sputtered film may be due to its low hydrogen content.

The DLC films deposited on Si. substrates acted as antireflective coatings, enhancing the infrared transmittance that was greatest at shorter wavelengths and that decreased with increasing wavelength. This antireflective property was observed for all of the DLC films deposited on Si, and therefore was independent of deposition method.

A spectrophotometer was used to measure the IR transmittance of the DLC films deposited on the $Z$ nS and ZnSe substrates. The spectral transmittance of the window material did not change in the wavelength region of 2.5 to $25 \mu \mathrm{m}$ for the ZnS and ZnSe substrates coated with $0.1-\mu m$-thick DLC films. The use of an intermediate Ge fllm or ion implantation also did not change the IR transmittance of $2 n S$ and ZnSe. Flgure 6 shows the specular IR transmittance of ZnS before and after implantation with 100-keV He ions at a dose of $5 \times 10^{16}$ particles $/ \mathrm{cm}^{2}$. The two traces fall on top of each other, indicating that there is no variation in the IR specular transmittance of ZnS after exposure to 
100-keV He ions. The intermediate coating of $\mathrm{Ge}$, which allows good DLC film adherence to $\mathrm{ZnS}$ and $\mathrm{ZnSe}$, shows only small reductions in IR specular transmittance especially at larger wavelengths. This is shown in figure 7 , where the IR specular transmittance of a ZnSe substrate coated with an intermediate layer of $0.03 \mu \mathrm{m}$ Ge and a $0.1-\mu \mathrm{m}$ DLC film from the single beam with $\mathrm{CH}_{4}$ is presented along with the transmittance of an uncoated ZnSe substrate. Although the IR specular transmittance is reduced at shorter wavelengths, only a 1 percent loss occurs at $10 \mu \mathrm{m}$. This reduction could be eliminated by picking the proper DLC and Ge thicknesses to allow the combination to become an antireflective coating.

\section{Erosion Tests}

To determine the protection the DLC films afforded the $\mathrm{ZnS}$ and $\mathrm{ZnSe}$, the surfaces were exposed to both $27-\mu \mathrm{m}$-diameter $\mathrm{Al}_{2} \mathrm{O}_{3}$ particles in a microsandblaster and water droplets at $180 \mathrm{~m} / \mathrm{sec}$ for exposure times up to $15 \mathrm{~min}$.

Particle erosion. - The erosion protection that the various DLC films afforded fused silica was first evaluated to determine the best method of coating the optical windows. For this test, 2- by 2-cm $\mathrm{SiO}_{2}$ samples were one-half coated with the DLC films and then placed in the sandblaster (refs. 5 and 12). Only half of the fused silica and half of the DLC film were then exposed to the $\mathrm{SiO}_{2}$ particles for various periods of time. The specular transmittance data were normalized to eliminate the uncertainty in the various parameters of the particle erosion test, and are presented in a manner that eliminates the exposure time and highlights the protection afforded by the DLC films. Figure 8 is the normalized specular transmittance after the erosion of uncoated fused silica and of fused silica coated with DLC films, 0.1 and $0.2 \mu \mathrm{m}$ thick, made by the single ion beam with $\mathrm{CH}_{4}$. The unprotected fused silica has a slope of one. It is clear that the DLC films extend the erosion lifetime of the fused silica and that the $0.2-\mu \mathrm{m}$ DLC film extends the lifetime more than the $0.1-\mu \mathrm{m}$ DLC film. The protection of the different ion beam deposited DLC $0.1-\mu \mathrm{m}$ films are presented in figure 9. The DLC films generated by ion beam sputter deposition and by either single or dual ion-beam deposition with $\mathrm{CH}_{4}$ protected the fused silica, and the protection appears to be independent of the deposition method. The ion beam sputter-deposited OLC films with the addition of hydrogen are also presented. These films eroded at a faster rate than the unprotected fused silica, thus making them less erosion resistant than the other DLC films.

The ZnS and ZnSe substrates were one-half coated with the DLC films that were determined to give the best erosion protection to fused silica and were exposed to the $\mathrm{Al}_{2} \mathrm{O}_{3}$ particles in the microsandblaster (ref. 6). Figures 10 and 11 indicate the change in specular transmittance at $10 \mu \mathrm{m}$ due to total erosion time for various surfaces of $Z n S$ and $Z n S e$, respectively, coated with the DLC films. In both figures there is an envelope that portrays the erosion rate of the uncoated surfaces. This envelope is necessary because each $Z n S$ and ZnSe substrate had a slightly different initial transmittance because the substrate thickness was not the same, although the erosion follows the same curve. The DLC films were $0.1 \mathrm{\mu m}$ thick, and were either sputter deposited from a graphite target or direct deposited from the single ion-beam source with $\mathrm{CH}_{4}$. An intermediate layer of $0.03-\mu \mathrm{m} G$ was used in all cases. Some of the $\mathrm{ZnS}$ and $Z$ nSe surfaces were also first He ion implanted at $100 \mathrm{keV}$ at doses of $0.5 \times 10^{17}$ and $2 \times 10^{17}$ particles $/ \mathrm{cm}^{2}$, and then coated with the DLC film from the 
single beam with $\mathrm{CH}_{4}$. As both figures indicate, neither the DLC films nor the ion implantation plus the DLC film afforded the ZnS and ZnSe surfaces any extension in particle erosion lifetime after exposure to the $\mathrm{Al}_{2} \mathrm{O}_{3}$ particles.

Rain erosion. - Only ZnS surfaces were evaluated for rain erosion performance in the facility at Wright Patterson Air Force Base. The Zns surfaces were first polished to a $20 / 10$ finish, but many small pits remained in the surface which could not be removed by polishing. This was undesirable since these pits could be a source of crack propagation during the rain erosion testing. zinc sulfide, DLC coated $2 n S$, and $2 n S$ that was first implanted with 100-keV He ions at a dose to $2 \times 10^{17}$ particles/cm2 and then coated with the DLC film were subjected to rain erosion. Although no quantitative data will be presented herein, it was clear from optically viewing the ZnS surfaces exposed to the water droplets at $400 \mathrm{mph}$ that there was a performance improvement in the ZnS surface that was ion implanted, coated with a $0.04-\mu \mathrm{m}$ intermediate layer of $\mathrm{Ge}$, and then coated with a $0.1-\mu m$ DLC film from the single beam with $\mathrm{CH}_{4}$. In comparison with ZnS or even ZnS windows coated with a $0.1-\mu m$-thick DLC film, the ion implantation plus the DLC coating decreased the number of new pits and delayed the start of subsurface ring fractures. This could be expected since the ion implantation improved the physical hardness ( $f i g .4$ ) at the surface to a depth of $\sim 1.0 \mu \mathrm{m}$ of the $\mathrm{ZnS}$ (ref. 9). There also were no changes in the specular transmittance between 2.5 and $25 \mu \mathrm{m}$ for the ion-implanted and DLC-coated ZnS surface after it was exposed to rain erosion.

Since ion implantation of the ZnS window resulted in improved performance, a ZnS surface was implanted with $\mathrm{He}^{+}$at $1 \mathrm{MeV}$ to further increase the depth of surface physical hardness. However, during the rain erosion test of this Zns surface (which was also coated with $0.1-\mu \mathrm{m}$ DLC and $0.04-\mu \mathrm{m} \mathrm{Ge}$ ), the ionimplanted surface layer delaminated from the ZnS substrate.

\section{CONCLUSIONS}

Three different ion beam methods were used to deposit diamondlike carbon (DLC) films on various substrates. The hydrogen content of the ion beam deposited DLC films was nearly one, while the ion beam sputter-deposited films had a relatively low H/C ratio even with the addition of hydrogen gas. The compressive stress exhibited by the DLC films did not depend on the hydrogen content, but on other parameters such as the deposition technique and conditions, and hydrocarbon gas. Elevated stress levels of DLC films that were ion beam deposited with $\mathrm{C}_{4} \mathrm{H}_{10}$ or ion beam sputter deposited from a graphite target indicated that thick films with good adherence on ZnS and ZnSe could not be generated.

Even though the DLC films on fused silica exhibited adherence as good as the maximum measurable adherence of the tester, these films were not as adherent on the $\mathrm{ZnS}$ and $\mathrm{ZnSe}$ substrates. Therefore, four techniques were used prior to the deposition of the DLC flims to improve the adherence. Ion beam cleaning and ion implantation did not increase film adherence. Ion implantation did, however, improve the physical hardness of the substrates. An intermediate coating of Ge successfully allowed the DLC films to remain adherent, and exhibited an adherence equal to the strength of the substrate. This intermediate Ge film caused a small reduction in the IR specular transmittance of $\mathrm{ZnS}$ and ZnSe at shorter wavelengths, but only a 1 percent loss occurred at $10 \mu \mathrm{m}$. 
Since the DLC films deposited on Si acted as an antireflective coating, thereby enhancing the IR transmittance, this reduction could be eliminated by picking the proper combination of DLC and Ge thicknesses to produce an antireflective coating.

Although ion implantation plus a DLC film did not protect the $\mathrm{ZnS}$ and $\mathrm{ZnSe}$ windows exposed to the simulated particle erosion, it did improve the performance of $\mathrm{ZnS}$ exposed to rain erosion. The $\mathrm{ZnS}$ windows that were He ion implanted and coated with DLC and an intermediate Ge layer had fewer new surface pits and a delayed start of subsurface ring cracks. Hardening the window surface itself by ion implantation, in addition to coating it with a thick stress-free diamondlike carbon $f i l m$, might increase the lifetime of infrared transmitting windows and protect them from both rain and less severe particle erosion.

\section{REFERENCES}

1. Nadler, M.P.; Donovan, T.M.; and Green, A.K.: Thermal Annealing Study of Carbon Films Formed by the Plasma Decomposition of Hydrocarbons. Thin Solid Films, vol. 116, no. 1-3, June 22, 1984, pp. 241-247.

2. Holland, L.; and Ojha, S.M.: Infrared Transparent and Amorphous Carbon Grown Under Ion Impact in a Butane Plasma. Thin Solid Films, vol. 48, no. 3, Feb. 1, 1978, pp. L21-L23.

3. Banks, B.A.; and Rutledge, S.K.: Ion Beam Sputter Deposited Diamond-Like Films. NASA TM-82873, 1982.

4. Mirtich, M.J.; Swec, D.M.; and Angus, J.C.: Dual Ion Beam Deposition of Carbon Films with Diamondlike Properties. NASA TM-83743, 1984.

5. Nir, D.: Mechanical Protection of DLC Films on Fused Silica Slides. NASA TM-87056, 1985.

6. SweC, D.M.; Mirtich, M.J.; Nir, D.; and Banks, B.A.: Comparison of Protective Coatings for Infrared Transmitting Windows. J. Vac. Sci. Technol. A, vol. 4, no. 6, Nov.-Dec. 1986, pp. 3030-3031.

7. Angus, J.C.; Stuitz, J.E.; Shiller, P.J.; McDonald, J.R.; Mirtich, M.J.; and Domitz, S.: Composition and Properties of the So-Called "DiamondLike" Amorphous Carbon Films. Thin Solid Films, vol. 118, no. 3, Aug. 17, 1984, pp. 311-320.

8. Mirtich, M.J.: Adherence of Ion Beam Sputter Deposited Metal Films on H-13 Steel. J. Vac. Sci. Technol., vol. 18, no. 2, Mar. 1981, pp. 186-189.

9. Mirtich, M.J.; Nir, D.; SweC, D.M.; and Banks, B.A.: The Use of Intermediate Layers to Improve the Adherence of Diamondlike Carbon Films on ZnS and ZnSe. J. Vac. Sci. Technol. A, vol. 4, 1986, pp. 2680-2681.

10. Bowman, R.L.; Mirtich, M.J.; and Weigand, A.J.: The Changes in Optical Properties of Various Transmitting Materials Due to Simulated Micrometeoroid Exposure. NASA TM X-52687, 1969. 
11. Angus, J.C.; Mirtich, M.J.; and Wintucky, E.G.: Ion Beam Deposition of Amorphous Carbon Fllms With Diamond Like Properties. Metastable Materials Formation by Ion Implantation, S.T. Picraux and W.J. Choyke, eds., North-Holland, 1982 , pp. 433-440.

12. Mirtich, M.J.; Nir, D.; Swec, D.M.; and Banks, B.A.: Diamondlike Carbon Protective Coatings for IR Materials. NASA TM-87083, 1985.

TABLE I. - PROPERTIES OF DIAMONDLIKE CARBON FILMS DEPOSITED BY DIFFERENT ION BEAM DEPOSITION METHODS

\begin{tabular}{|l|l|c|}
\hline $\begin{array}{c}\text { Deposition } \\
\text { method }\end{array}$ & $\begin{array}{l}\text { Stress, } \\
\text { dyne/ } \mathrm{cm}^{2}\end{array}$ & $\begin{array}{c}\text { Hydrogen content, } \\
\mathrm{H} / \mathrm{C}\end{array}$ \\
\hline Single beam, $\mathrm{CH}_{4}$ & $0.9 \times 10^{10}$ & 0.91 \\
Single beam, $\mathrm{C}_{4}{ }^{\mathrm{H}} 10$ & 2.6 & .62 \\
Dual beam, $\mathrm{CH}_{4}$ & .9 & .62 \\
& & .22 \\
Graphite sputtering & 1.6 & .53 \\
Graphite sputtering & 2.3 & \\
$+\mathrm{H}_{2}$ addition & & \\
\hline
\end{tabular}




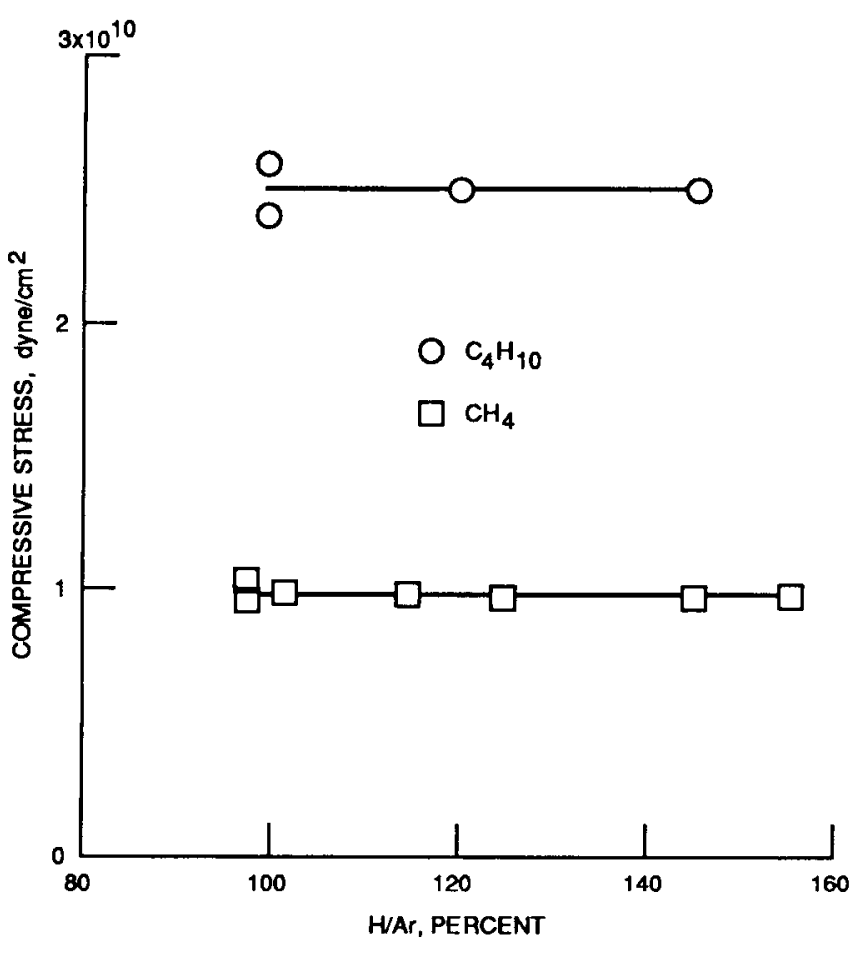

Figure 1. - Compressive stress as function of H/Ar gas ratio for $0.1-\mu \mathrm{m}$-thick DLC films made with $\mathrm{CH}_{4}$ and $\mathrm{C}_{4} \mathrm{H}_{10}$ in the single ionbeam source at $110 \mathrm{eV}$.

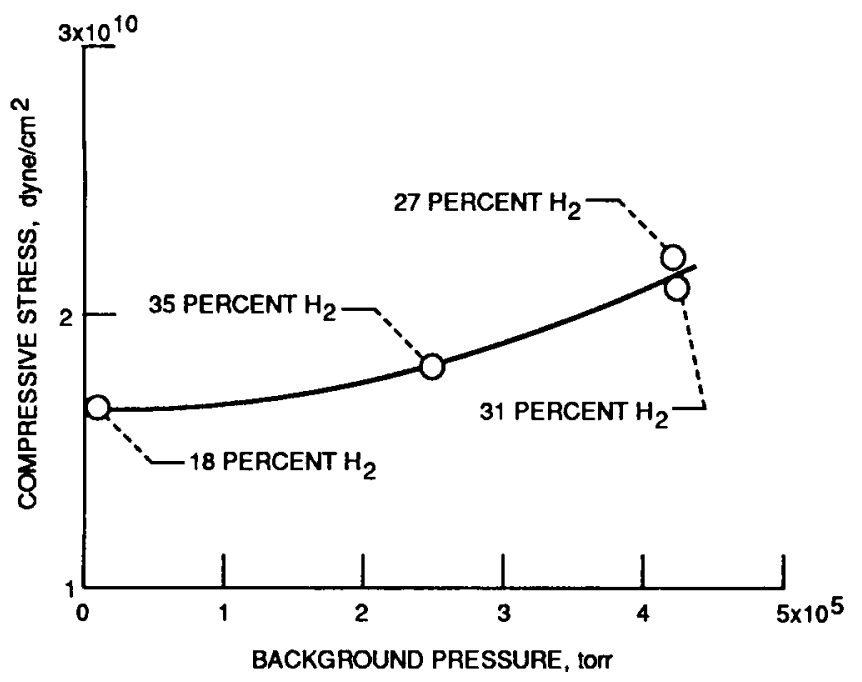

Figure 3. - Compressive stress as function of background pressure for $0.1-\mu \mathrm{m}$-thick DLC films sputter deposited from a graphite target with the addition of $\mathrm{H}_{2}$ into the vacuum facility.

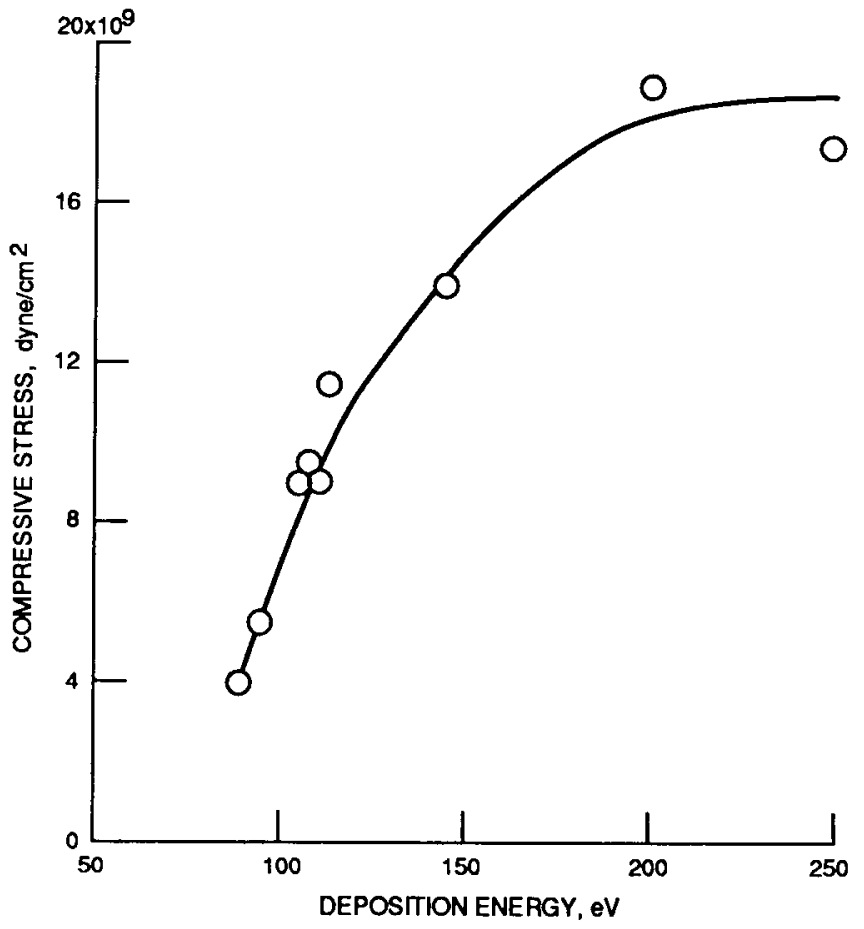

Figure 2. - Compressive stress as function of deposition energy for $0.1-\mu \mathrm{m}$-thick DLC films made with $\mathrm{CH}_{4}$ in the single ion-beam source.

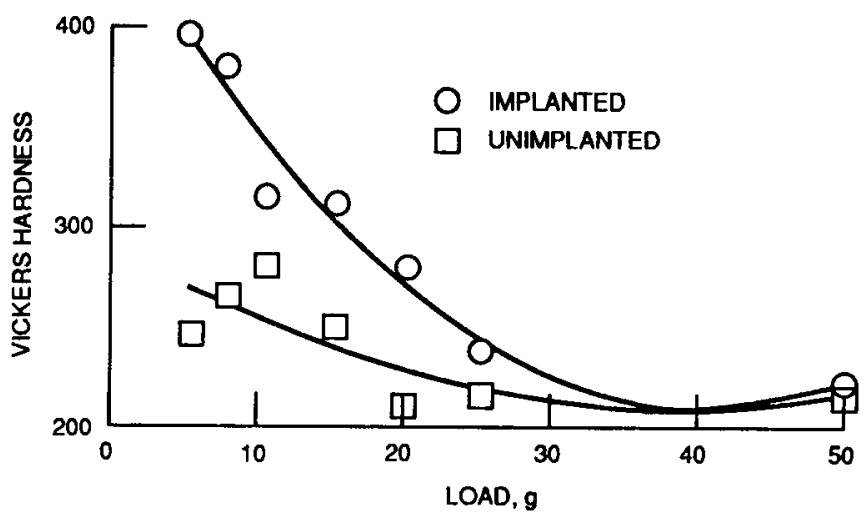

Figure 4. - Vickers hardness as function of applied load for unimplanted $\mathrm{ZnS}$, and for ZnS implanted with He ions, at $100 \mathrm{keV}$ at a dose of $2 \times 10^{17}$ particles $/ \mathrm{cm}^{2}$. 


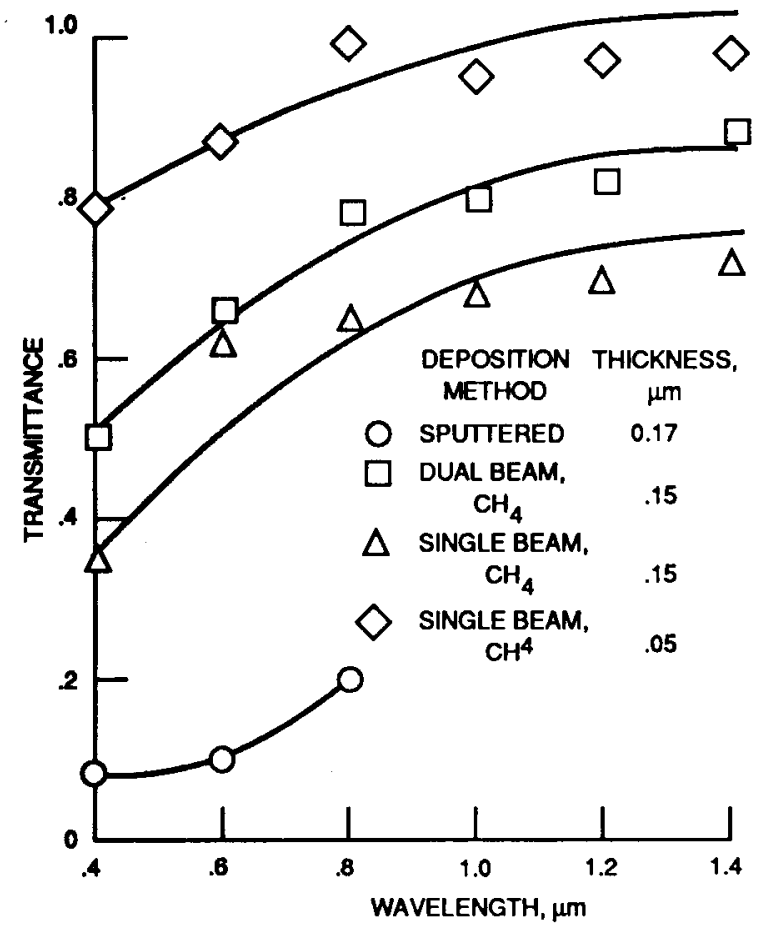

Figure 5. - Transmittance as function of wavelength for DLC films made with $\mathrm{CH}_{4}$ in the single or dual ionbeam source, and DLC films made by sputter deposition of a graphite target.

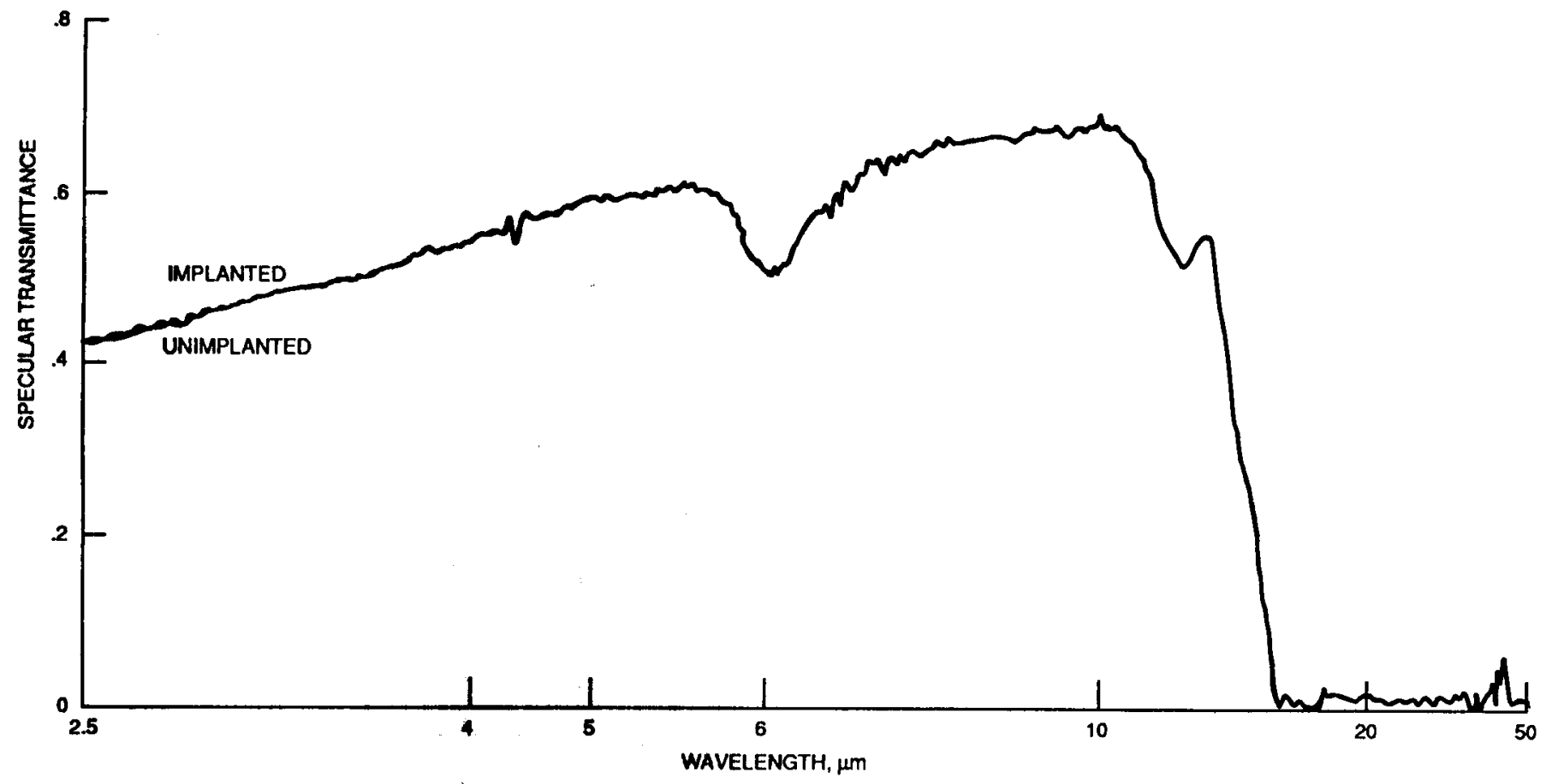

Figure 6. - Specular tranemitunce of Ins before and after He lon Implantation at $100 \mathrm{keV}$ at a dose of $5 \times 10^{16}$ particles/ cm 2 .

11 


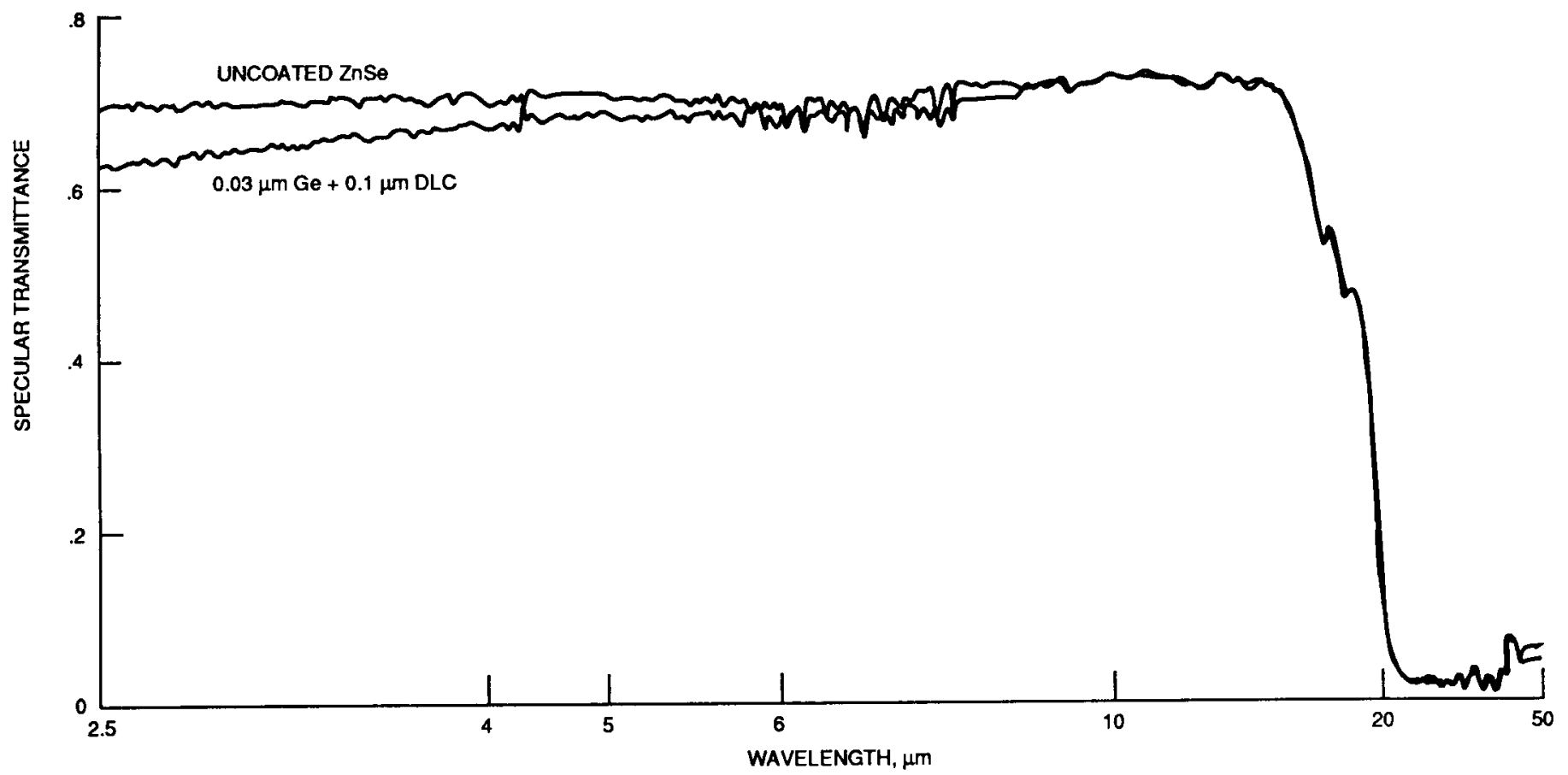

Figure 7. - Specular transmittance of $0.1-\mu \mathrm{m} \mathrm{DLC} \mathrm{film} \mathrm{made} \mathrm{with} \mathrm{CH}_{4}$ in the single beam with and without an intermediate layer of $0.03-\mu \mathrm{m}$ Ge on the ZnSe substrate.

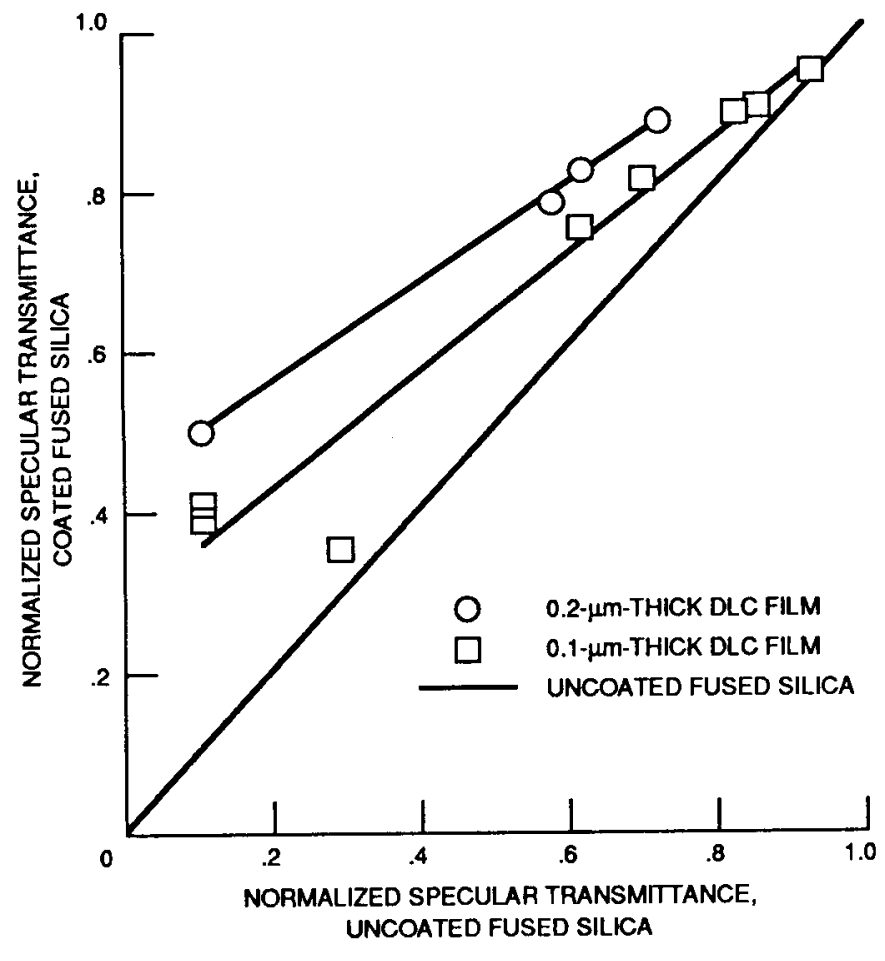

Figure 8. - Normalized specular transmittance of fused silica coated with DLC films, 0.1 and $0.2 \mu \mathrm{m}$ thick, made with $\mathrm{CH}_{4}$ in the single ion-beam source, and uncoated fused sillca, both after exposure to $100-\mu \mathrm{m} \mathrm{SiO} 2$ particles at $27 \mathrm{~m} / \mathrm{sec}$.

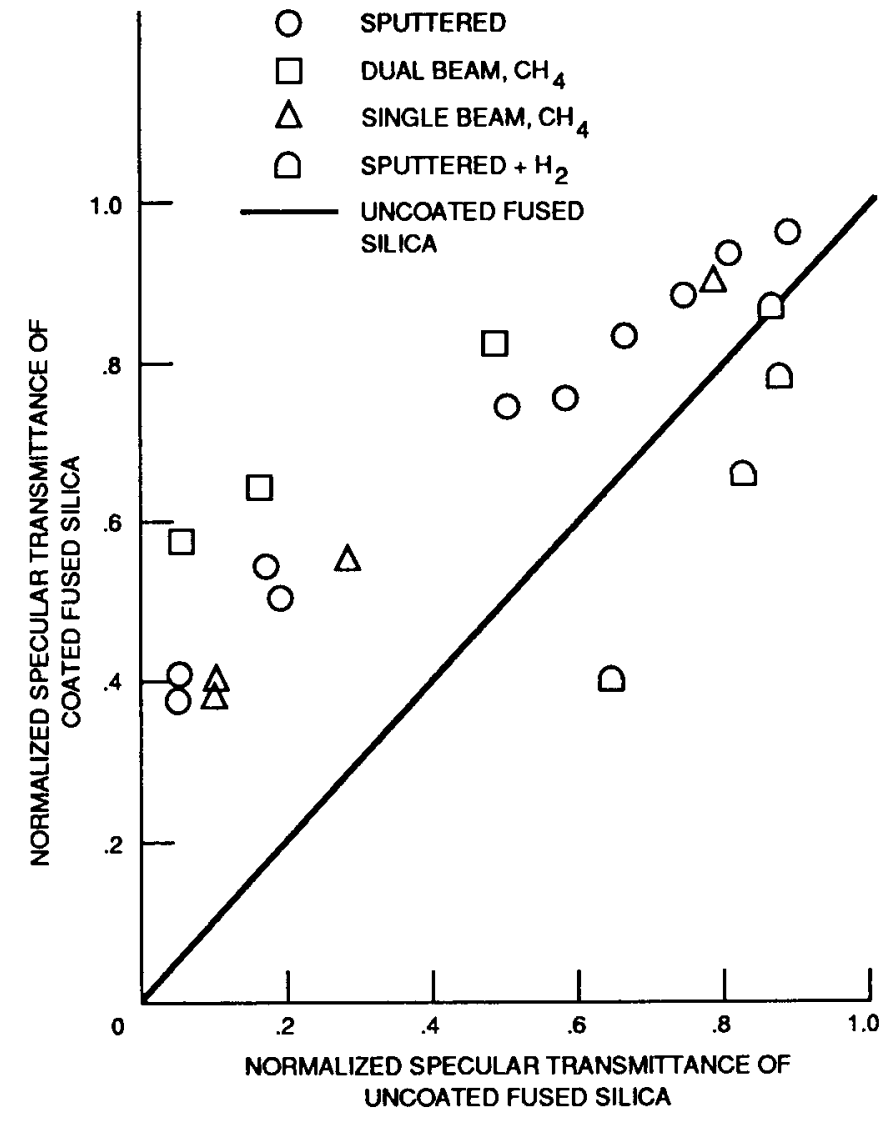

Figure 9. - Protection that $0.1-\mu m$-thick DLC films deposited by various methods afforded fused silica after exposure to $100-\mu \mathrm{m}$ $\mathrm{SiO}_{2}$ particles at $27 \mathrm{~m} / \mathrm{sec}$. 


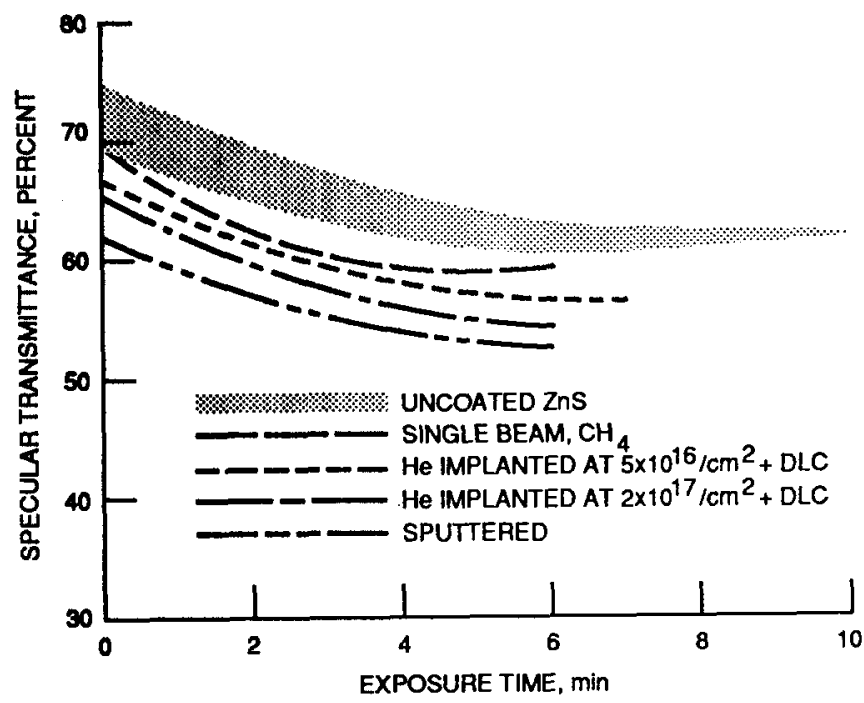

Floure 10. - Change in specular transmittance at $10 \mu \mathrm{m}$ due to total orosion time for various surlaces of $Z n S$ coated with DLC films.

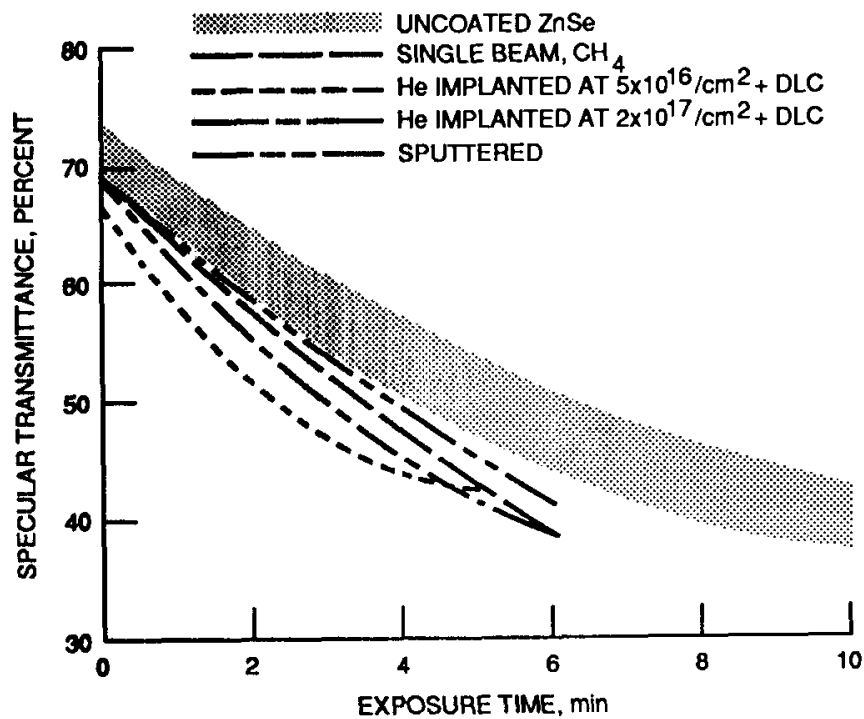

Figure 11. - Change in specular transmittance at $10 \mu \mathrm{m}$ due to total erosion time for various surfaces of ZnSe coated with DLC films. 


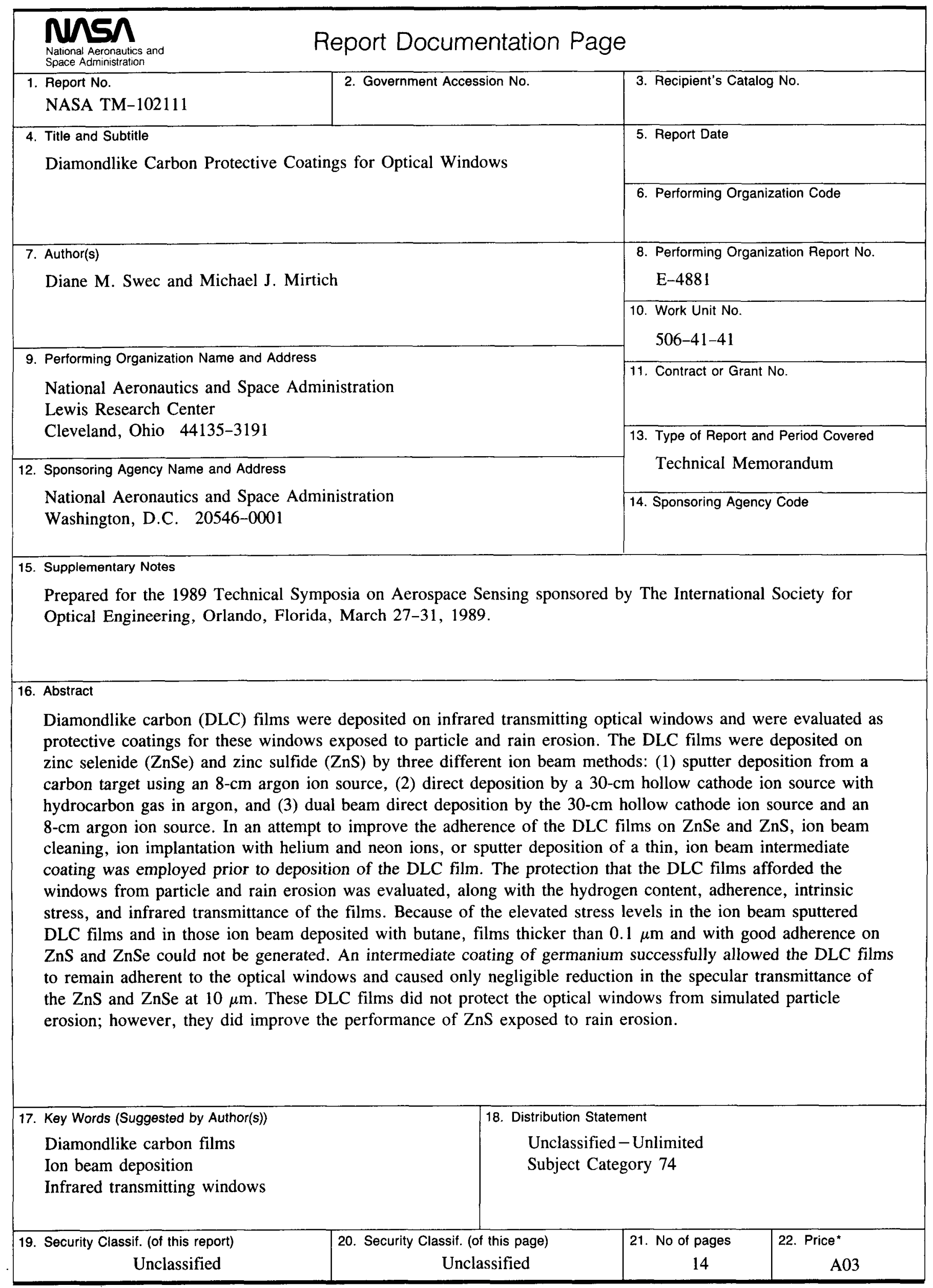

